\title{
Letrozole versus tamoxifen for ovulation induction in non-polycystic ovarian syndrome anovulatory infertile females
}

\author{
Eman Ahmed Kishk
}

Department of Obstetrics and Gynecology, Faculty of Medicine, Suez Canal University, Egypt

\begin{abstract}
Background: Anovulation is the most common cause for infertility, different oral agents are used for induction of ovulation, tamoxifen may be effective as letrozole in this era.

Objective: The aim of this study was to compare the effectiveness of tamoxifen and letrozole in terms of ovulation induction outcomes in non PCOS anovulatory patients.

Patients and Methods: This randomized single blinded clinical trial was conducted among a total of 120 patients with anovulatory infertility that were randomized to one of two treatment arms: Letrozole group and Tamoxifen group. The treatment was continued for three consecutive cycles. Main outcome measures were number of follicles $\geq 18 \mathrm{~mm}$, endometrial thickness and ovulation rate. Secondary outcomes measures were cumulative pregnancy rate and spontaneous abortion rates.

Results: Mean number of mature of follicles $\geq 18 \mathrm{~mm}$ was statistically significantly higher in Tamoxifen group (1.9 \pm 1.1$)$ when compared to Letrozole group $(1.5 \pm 0.9)$ with $p$-value $=0.03$. Also, endometrial thickness was significantly different between both groups; as it was higher in Tamoxifen group $(8.2 \pm 1.6 \mathrm{~mm}$ versus $7.08 \pm 2.4 \mathrm{~mm})$ in Letrozole group $(p$-value $=0.02)$. No significant difference was reported between both groups as regarding ovulation rate, pregnancy rate and spontaneous abortion rate, ovulation rate was $73.3 \%$ with Letrozole and $63.3 \%$ with Tamoxifen $(P=0.3)$, cumulative pregnancy rate was 30\% with Letrozole group and $23.3 \%$ with Tamoxifen group $(p=0.5)$ and spontaneous abortion rate was 3.3\% in Letrozole group and $5 \%$ in Tamoxifen group $(p=0.9)$.

Conclusion: Tamoxifen drug has comparable ovulation induction outcomes to letrozole with very low costs and side effects. Tamoxifen could be considered suitable for ovulation induction in developing countries.
\end{abstract}

Key Words: Anovulation, infertility, letrozole, ovulation induction, tamoxifen

Received:01 March 2019, Accepted: 01 May 2019

Corresponding Author: Eman A. Kishk, MD, Department of Obstetrics and Gynecology, Faculty of Medicine, Suez-Canal University, Egypt, Tel.: 01288746331, E-mail: k_tawfic@yahoo.com

ISSN: 2090-7265, May 2019, Vol.9, No. 2

\section{INTRODUCTION}

Anovulation is the most common cause for infertility; it represents $20-25 \%$ of all cases of infertility ${ }^{[1]}$. Tamoxifen is a triphenylethylene that closely resembles clomophine citrate (CC). The use of tamoxifen for ovulation induction has been the subject of clinical investigation since the early 1970s. Klopper and Hall were the first to describe successful results with tamoxifen for the induction of ovulation in women suffering from secondary amenorrhea ${ }^{[2]}$.

Previous studies reported the value of tamoxifen in corpus luteum insufficiency and inadequate cervical mucus secretion ${ }^{[3]}$. Previous clinical trials with tamoxifen demonstrated that the overall ovulation and pregnancy rates were similar or superior to $\mathrm{CC}$ and does not appear to have an adverse impact on the endometrium ${ }^{[4]}$.
Another oral agent that has been recently introduced to the era of ovulation is letrozole. Aromatase inhibitors were first used in ovulation induction in $2001^{[5-7]}$. Letrozole is a third-generation aromatase inhibitor blocks the conversion of androgens to estrogens in the ovarian follicles, peripheral tissues, and in the brain, this leads to fall in circulating and local estrogens and release the hypothalamopituitary axis from the negative feedback of estrogens. Thus, there is a surge in follicle stimulating hormone (FSH) release, which results in follicular growth. Since, the feedback mechanism is intact; normal follicular growth, selection of dominant follicle, and atresia of smaller growing follicle occurs; and thereby facilitating monofollicular growth and ovulation ${ }^{[8]}$.

Aromatase inhibitors increases intraovarian androgens thereby increases the follicular sensitivity to FSH. Androgen has a role in early follicular developments by 
augmenting FSH receptors and stimulating insulin-like growth factor (IGF)-I; FSH and IGF-I act synergistically to promote follicular growth ${ }^{[9]}$.

Most of the previous studies have compared the effectiveness of ovulation induction agents regardless of the costs which is an important issue in developing countries.

\section{AIM OF THE WORK}

In the present study, we aimed to compare effectiveness of letrozole as a relatively expensive oral agent and tamoxifen as cheap agent in terms of ovulation induction outcomes.

\section{PATIENTS AND METHODS}

This randomized single blinded clinical trial was conducted at Suez Canal University Hospital, the study protocol was approved by the ethics committee and an informed written consent was obtained from all participants.
Inclusion criteria were infertile women aged 20-35 years, BMI $<30 \mathrm{~kg} / \mathrm{m} 2$, with either primary or secondary type of infertility and eligible for ovulation induction after exclusion of male factor by normal seminogram, normal hormonal profile [follicle-stimulating hormone (FSH), luteinizing hormone ( $\mathrm{LH})$, thyroid stimulating hormone (TSH) and prolactin hormone], normal uterine cavity and patent fallopian tubes based on hysterosalpingography (HSG) or laparoscopy and no history of ovulation induction in the previous 3 months.

Required sample size was estimated based on power of study of $90 \%$ and $\alpha$ error of $0.05^{[10]}$. Every patient was followed for 3 consecutive cycles.

\section{Randomization and treatment arms:}

Women $(n=124)$ were randomized into two groups, group A included 62 patients received letrozole while group $\mathrm{B}$ included another 62 patients received tamoxifen. A total of 120 patients had completed the study (60 patients in each group), as 4 cases were lost during follow up period (Figure 1).

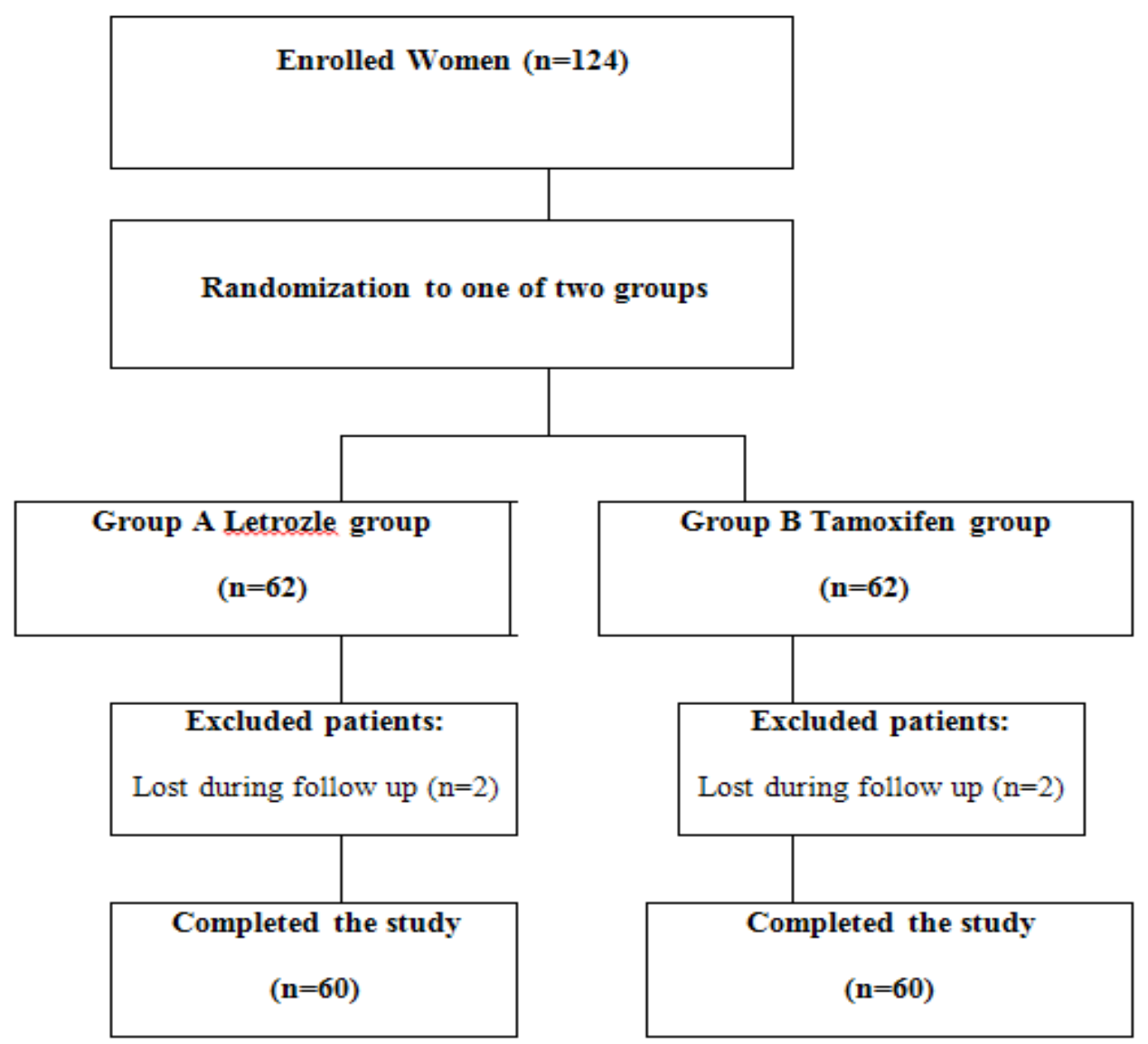

Fig. 1: Flow chart of the studied population 
Transvaginal ultrasonography (TVS) was done on the $3^{\text {rd }}$ day of the menstrual cycle (for exclusion of any ovarian cysts), induction of ovulation in letrozole group was started with letrozole $2.5 \mathrm{mg}$ tablet (Femara ${ }^{\circledR}$, Novartis CO., Egypt) once daily and tamoxifen $10 \mathrm{mg}$ tablet (Tamofen ${ }^{\circledR}$, Al-Amarya CO., Egypt) once daily in tamoxifen group started from the $3^{\text {rd }}$ day to the $7^{\text {th }}$ day of the cycle.

If ovulation failed to occur with the initial dose of either drug, the daily dosage was increased in letrozole group by $2.5 \mathrm{mg}$ increment in subsequent cycle to 5 and $7.5 \mathrm{mg}$ in subsequent cycles and in tamoxifen group by $10 \mathrm{mg}$ increment in subsequent cycle to 20 and $30 \mathrm{mg}$. Treatment has been stopped if they became pregnant or if patient did not ovulate with maximum dose and these patients were classified as treatment resistant or failed to concept after three months despite ovulation and these patients were labeled as treatment failure. Also, if intolerable symptoms as depression, severe headache or dizziness, pain and vision changes had occurred treatment was discontinued.

Serial folliculometry was done by TVS starting day 8 of menstrual cycle till at least one follicle reached $\geq 18 \mathrm{~mm}$. Endometrial thickness was assessed prior to Human Chorionic Gonadotrophin (HCG) administration (10000 IU) (Epifassi ${ }^{\circledR}$, EPICO CO., Egypt) followed by intercourse after 24 to 36 hours. Serum beta human chorionic gonadotropin (B-hCG) was checked after two weeks to confirm pregnancy. Gestational sac was assessed by transvaginal ultrasonography at $6^{\text {th }}$ week of gestation.

\section{Outcome measures:}

Main outcome measures were number of follicles $\geq 18 \mathrm{~mm}$, endometrial thickness and ovulation rate. Secondary outcome measures were clinical pregnancy rates and spontaneous abortions rates.

\section{STATISTICAL ANALYSIS}

Data were processed using SPSS version 15 (SPSS Inc., Chicago, IL, USA). Quantities data were expressed as means $\pm \mathrm{SD}$ and qualitative data were expressed as numbers and percentages. Student's T-test was used to test significance of difference for quantitative variables while Chi-square and fisher's exact tests were used to test significance for qualitative variables. A probability value $(p$-value $)<0.05$ was considered statistically significant.

\section{RESULTS}

Table 1 shows that patients of both groups were matched as regarding age, body mass index (BMI), duration and type of infertility. Mean age was $28.72 \pm 5.5$ years in letrozole group and $26.1 \pm 5.8$ years in tamoxifen group (p-value $>0.05)$. BMI was $24.9 \pm 3.2$ and $25.4 \pm 2.9 \mathrm{~kg} / \mathrm{m} 2$ in letrozole and tamoxifen respectively, with no significant difference. Mean duration of infertility was $4.6 \pm 1.9$ years in letrozole group and $5.2 \pm 2.4$ years in tamoxifen group ( $p$-value $>0.05), 90 \%$ of the letrozole group and $86.7 \%$ of tamoxifen group were classified as primary infertility ( $p$-value $>0.05)$.

As regarding primary outcome measures, tamoxifen showed significantly higher endometrial thickness $(8.2 \mathrm{~mm}$ versus $7.08 \mathrm{~mm})$ compared to letrozole group ( $p$-value $=0.02)$. Number of follicles $\geq 18 \mathrm{~mm}$ was significantly higher with tamoxifen group (1.9 mm versus $1.5 \mathrm{~mm}$ among letrozole group patients; $p$-value $=0.03$ ). No significant difference was reported between both groups as regarding ovulation rate, pregnancy rate, spontaneous abortion rate, treatment resistance rate and treatment failure rate. Ovulation rate was $73.3 \%$ with letrozole and $63.3 \%$ with tamoxifen. Cumulative pregnancy rate was $30 \%$ with letrozole and $23.3 \%$ with tamoxifen group. None of patients of letrozole and tamoxifen groups have multiple pregnancies (Table 2).

Table 1: Baseline characteristics among the studied patients in both group:

\begin{tabular}{|c|c|c|c|c|c|}
\hline Characteristics & & \multicolumn{2}{|c|}{$\begin{array}{l}\text { Letrozole group } \\
(\mathrm{n}=60)\end{array}$} & $\begin{array}{l}\text { Tamoxifen group } \\
(\mathrm{n}=60)\end{array}$ & \multirow{2}{*}{$\frac{p \text {-value }}{0.09 \text { (NS) }}$} \\
\hline Age (Years) & Mean \pm SD & \multicolumn{2}{|c|}{$28.72 \pm 5.5$} & $26.1 \pm 5.8$ & \\
\hline BMI (kg/m2) & Mean \pm SD & \multicolumn{2}{|c|}{$24.9 \pm 3.2$} & $25.4 \pm 2.9$ & $0.3(\mathrm{NS})$ \\
\hline $\begin{array}{l}\text { Primary infertility } \\
\text { Secondary infert. }\end{array}$ & & $\begin{array}{l}54 \\
6\end{array}$ & $\begin{array}{l}90 \% \\
10 \%\end{array}$ & $\begin{array}{ll}52 & 86.7 \% \\
8 & 13.3 \%\end{array}$ & $0.78(\mathrm{NS})$ \\
\hline $\begin{array}{l}\text { Duration of } \\
\text { infertility (Years) }\end{array}$ & Mean \pm SD & & $=1.9$ & $5.2 \pm 2.4$ & $0.6(\mathrm{NS})$ \\
\hline
\end{tabular}

NS: No statistically significant difference 
Table 2: Outcome measures among both groups:

\begin{tabular}{lccc}
\hline Characteristics & Mean \pm SD & $\begin{array}{c}\text { Letrozole group } \\
(\mathrm{n}=60)\end{array}$ & $\begin{array}{c}\text { Tamoxifen group } \\
(\mathrm{n}=60)\end{array}$ \\
\hline $\begin{array}{l}\text { Number of follicles } \\
\geq 18 \mathrm{~mm}\end{array}$ & $\begin{array}{c}\text { Mean } \pm \mathrm{SD} \\
\text { Range }\end{array}$ & $1.5 \pm 0.9$ & $1.9 \pm 1.1$ \\
$\begin{array}{l}\text { Endometrial } \\
\text { thickness }(\mathrm{mm})\end{array}$ & $7.08 \pm 2.4$ & $8.2 \pm 1.6$ \\
$\begin{array}{l}\text { Ovulation rate } \\
\text { Pregnancy rate }\end{array}$ & $6-10$ & $7-12$ \\
$\begin{array}{l}\text { Spontaneous } \\
\text { abortion rate }\end{array}$ & $44(73.3 \%)$ & $38(63.3 \%)$ & $0.02 *$ \\
Treatment resistance & $18(30 \%)$ & $0.3(\mathrm{NS})$ \\
Treatment failure & $2(3.3 \%)$ & $3(5 \%)$ & $0.5(\mathrm{NS})$ \\
\hline
\end{tabular}

*Statistically significant difference

NS: Not statistically significant difference

\section{DISCUSSION}

This study compares two oral ovulation induction agents (Letrozole and Tamoxifen) among non-PCOS anovulatory women. To the best of our knowledge, few studies have compared both letrozole and tamoxifen as ovulation induction agents as most of the available studies compare them to the most widely used ovulation induction agent clomiphene citrate.

The present study has shown that both letrozole and tamoxifen have comparable ovulation and pregnancy rates $(73.3 \%$ versus $63.3 \%$ and $30 \%$ versus $23.3 \%)$ with no statistically significant difference. Previous studies have shown similar rate of pregnancy as for letrozole. Hendawy and colleagues ${ }^{[1]}$ have shown that pregnancy rate among PCOS women with use of letrozole to be $33 \%$. Other previous results showed consistent findings ${ }^{[12,13]}$.

In accordance with the present study, Seyedoshohadaei et al., ${ }^{[14]}$ have compared effectiveness of letrozole, tamoxifen along with $\mathrm{CC}$ as regard pregnancy rate and ovulation rates among non-PCOS females. As regarding difference between letrozole and tamoxifen, no significant difference was reported. Ovulation rates reported in their study were consistent with the present findings (74\% and $68 \%$ for letrozole and tamoxifen, respectively) while pregnancy rates were higher $(50 \%$ and $40 \%$ for letrozole and tamoxifen, respectively $)^{[15]}$. This difference in pregnancy rate may be due to the duration of follow up was longer in their study (6 months) versus 3 months in the present study.

Other previous reports evaluating the effectiveness of letrozole have shown consistent findings ${ }^{[15,16]}$.
Elnashar et al. ${ }^{[16]}$ reported an ovulation rate of $54.6 \%$ and pregnancy rate of $25 \%$ with letrozole induction in clomiphene citrate-resistant women with PCOS and Ganesh et al., ${ }^{[15]}$ reported the ovulation rate of $79.3 \%$ and the pregnancy rate of $23.39 \%$ with letrozole.

We have found that endometrial thickness and number of follicles were significantly higher with the use of tamoxifen. Letrozole- unlike CC- has shorter half-life and thus has lower peripheral anti-estrogen effect $^{[17]}$ with little effect on endometrial thickness. Consistently $\mathrm{Abu}$ Hashim et al., ${ }^{[18]}$ reported that endometrial thickness on 14 cycles had no significant increase in the letrozole group. Unlike the present study, Seyedoshohadaei et al., ${ }^{[14]}$ has reported higher endometrial thickness with letrozole than tamoxifen but with no statistically significant difference ${ }^{[14]}$.

Most of the available reports on tamoxifen as oral ovulation induction agents have shown consistent findings with the present study. In accordance with the present findings, Dhaliwal et al. ${ }^{[1]}$ has reported ovulation rate of $68 \%$ and pregnancy rate of $16.5 \%$. They have also reported significant increase in both ovulation and pregnancy rate with doubling Tamoxifen daily dosage from $40 \mathrm{mg}$ to $80 \mathrm{mg}^{[1]}$.

An earlier study by Williamson et al., ${ }^{[19]}$ reported an ovulation rate of $81 \%$ which is even higher than the rate reported in the present study. In another study by Messinis et al., ${ }^{[20]}$ the ovulation rate was $76.08 \%$ that is similar to the present finding. Tamoxifen improves folliculogenesis process by blocking oestradiolbinding sites on the hypothalamic-pituitary axis and preventing the negative feedback effect of oestradiol, so increasing gonadotrophin secretion improves function 
of the corpus luteum, in addition to its beneficial effects on the cervical mucus and endometrium receptivity ${ }^{[3]}$. So, tamoxifen may be used to increase pregnancy rate.

The present study has shown that both tamoxifen and letrozole are tolerable drugs and not associated with serious side effects. Consistently Williamson et $a .^{[19]}$ and Klopper et al., ${ }^{[2]}$ did report mild side-effects in the form of headache and mild ovarian enlargement. Also, more recently and in accordance with the present study, Dhaliwal et al., ${ }^{[1]}$ and Seyedoshohadaei et al., ${ }^{[14]}$ didn't report any serious side effects with tamoxifen.

One of the most important advantages of both agents is very low rates of multiple pregnancies ${ }^{[1,12,21]}$. Consistent with the available reports, we have reported no cases of multiple pregnancies with either drug.

\section{CONCLUSION}

Both letrozole and tamoxifen are effective ovulation induction agents with comparable ovulation and pregnancy rates and rare incidence of multiple pregnancies and few tolerable side effects. Further researches should be directed toward the clinical and routine use of tamoxifen in field of ovulation induction due to appreciable advantages as high pregnancy and ovulation rates and low multiple pregnancy rates, tolerable side effects and low price. The major limitation of the present study is that we have followed patients for only three consecutive cycles.

\section{CONFLICT OF INTEREST}

There are no conflict of interests.

\section{REFERENCES}

1. Dhaliwal LK, Suri V, Gupta KR, and Sahdev S. Tamoxifen: An alternative to clomiphene in women with polycystic ovary syndrome. J Hum Reprod Sci. 2011; 4(2): 76-79.

2. Klopper A, Hall M. New synthetic agent for the induction of ovulation: Preliminary trials in women. Br Med J. 1971; 1:152-154.

3. Deligdisch L. Hormonal pathology of the endometrium. Modern Pathology 2000; 13: 285-294.

4. Pandey S. Singh U, Arora S. Arora R. Ovulation Induction: A Comparison between Clomiphene and Tamoxifen. J. Biol. Chem. Research. 2007; 24 (1\& 2): 13-18.
5. Sammour A, Biljan MM, Tans SL, Tulandi T. Prospective randomized trial comparing the effects of letrozole and clomiphene citrate on follicular development, endometrial thickness and pregnancy rate in patients undergoing superovulation prior to intrauterine insemination. Fertil Steril 2001; 76 (Suppl 1): S110.

6. Mitwally MF, Casper RF. Use of an aromatase inhibitor for induction of ovulation in patients with an inadequate response to clomiphene citrate. Fertil Steril 2001; 75:305-309.

7. Holzer H, Casper R, Tulandi T. A new era in ovulation induction. Fertil Steril. 2006; 85:277-284.

8. Kamat A, Hinshelwood MM, Murry BA, Mendelson CR. Mechanisms in tissue-specific regulation of estrogen biosynthesis in humans. Trends Endocrionol Metab 2002; 133:122128-.

9. Vendola K, Zhou J, Wang J, et al. Androgens promote oocyte insulin-like growth factor I expression and initiation of follicle development in the primate ovary. Biol Reprod 1999; 61:353-357.

10. Fleiss JL. Statistical Methods for Rates and Proportions. John Wiley \& Sons, Inc., New York, 1981.

11. Hendawy SF, Samaha HE, Elkholy MF. Letrozole versus Clomiphene Citrate for Induction of Ovulation in Patients with Polycystic Ovarian Syndrome Undergoing Intrauterine Insemination. Clinical Medicine Insights: Reproductive Health 2011:5 11-16

12. Mitwally MF, Biljan MM, Casper RF. Pregnancy outcome after the use of an aromatase inhibitor for ovarian stimulation. Am J Obstet Gynecol 2005; 192: 381-386.

13. Zeinalzadeh M, Basirat Z, Esmailpour M. Efficacy of letrozole in ovulation induction compared to that of clomiphene citrate in patients with polycystic ovarian syndrome. J Reprod Med. 2010; 55:36-40.

14. Seyedoshohadaei F, Zandvakily F, Shahgeibi S. Comparison of the effectiveness of clomiphene citrate, tamoxifen and letrozole in ovulation induction in infertility due to isolated unovulation. Iran J Reprod Med. 2010; 10(6): 531-536.

15. Ganesh A, Goswami SK, Chattopadhyay R, Chaudhury K, Chakravarty B. Comparison 
of letrozole with continuous gonadotropins and clomiphene-gonadotropin combination for ovulation induction in 1387 PCOS women after clomiphene citrate failure: a randomized prospective clinical trial. J Assist Reprod Genet 2009; 26: 19-24.

16. Elnashar A, Fouad H, Eldosoky M, Saeid N. Letrozole induction of ovulation in women with clomiphene citrate-resistant polycystic ovary syndrome may not depend on the period of infertility, the body mass index, or the luteinizing hormone/follicle-stimulating hormone ratio. Fertil Steril 2006; 85: 511-513

17. Fisher SA, Reid RL, Van Vugt DA, Casper RF. A randomized double-blind comparison of the effects of clomiphene citrate and the aromatase inhibitor letrozole on ovulatory function in normal women. Fertil Steril 2002; 78: 280-285.
18. Abu Hashim H, Shokeir T, Badawy A. Letrozole versus combined metformin and clomiphene citrate for ovulation induction in clomipheneresistant women with polycystic ovary syndrome: a randomized controlled trial. Fertil Steril 2010; 94: 1405-1409.

19. Williamson JG, Ellis JD. The induction of ovulation by tamoxifen. J Obstet Gynecol Brit Commonw. 1973; 80:844-847.

20. Messinis IE, Nillius SJ. Comparison between tamoxifen and clomiphene therapy for induction of ovulation. Acta Obstet Gynaecol Scand. $1982 ; 61: 377-379$.

21. Casper RF. Letrozole: Ovulation or superovulation? Fertil Steril. 2003;80: 1335-1337. 